
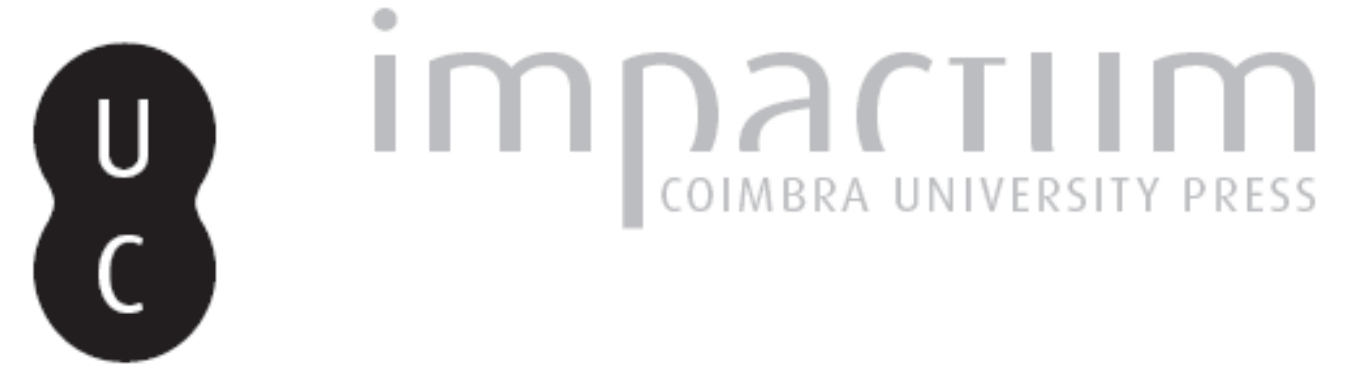

\title{
O último Foucault e o retorno transversal aos gregos
}

\section{Autor(es): $\quad$ Gomes, Daniel de Oliveira}

Publicado por: Annablume Clássica; Imprensa da Universidade de Coimbra

URL persistente:

URI:http://hdl.handle.net/10316.2/24303

DOI:

DOI:http://dx.doi.org/10.14195/1984-249X_9_4

Accessed : $\quad$ 26-Apr-2023 16:30:00

A navegação consulta e descarregamento dos títulos inseridos nas Bibliotecas Digitais UC Digitalis, UC Pombalina e UC Impactum, pressupõem a aceitação plena e sem reservas dos Termos e Condições de Uso destas Bibliotecas Digitais, disponíveis em https://digitalis.uc.pt/pt-pt/termos.

Conforme exposto nos referidos Termos e Condições de Uso, o descarregamento de títulos de acesso restrito requer uma licença válida de autorização devendo o utilizador aceder ao(s) documento(s) a partir de um endereço de IP da instituição detentora da supramencionada licença.

Ao utilizador é apenas permitido o descarregamento para uso pessoal, pelo que o emprego do(s) título(s) descarregado(s) para outro fim, designadamente comercial, carece de autorização do respetivo autor ou editor da obra.

Na medida em que todas as obras da UC Digitalis se encontram protegidas pelo Código do Direito de Autor e Direitos Conexos e demais legislação aplicável, toda a cópia, parcial ou total, deste documento, nos casos em que é legalmente admitida, deverá conter ou fazer-se acompanhar por este aviso.

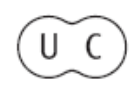




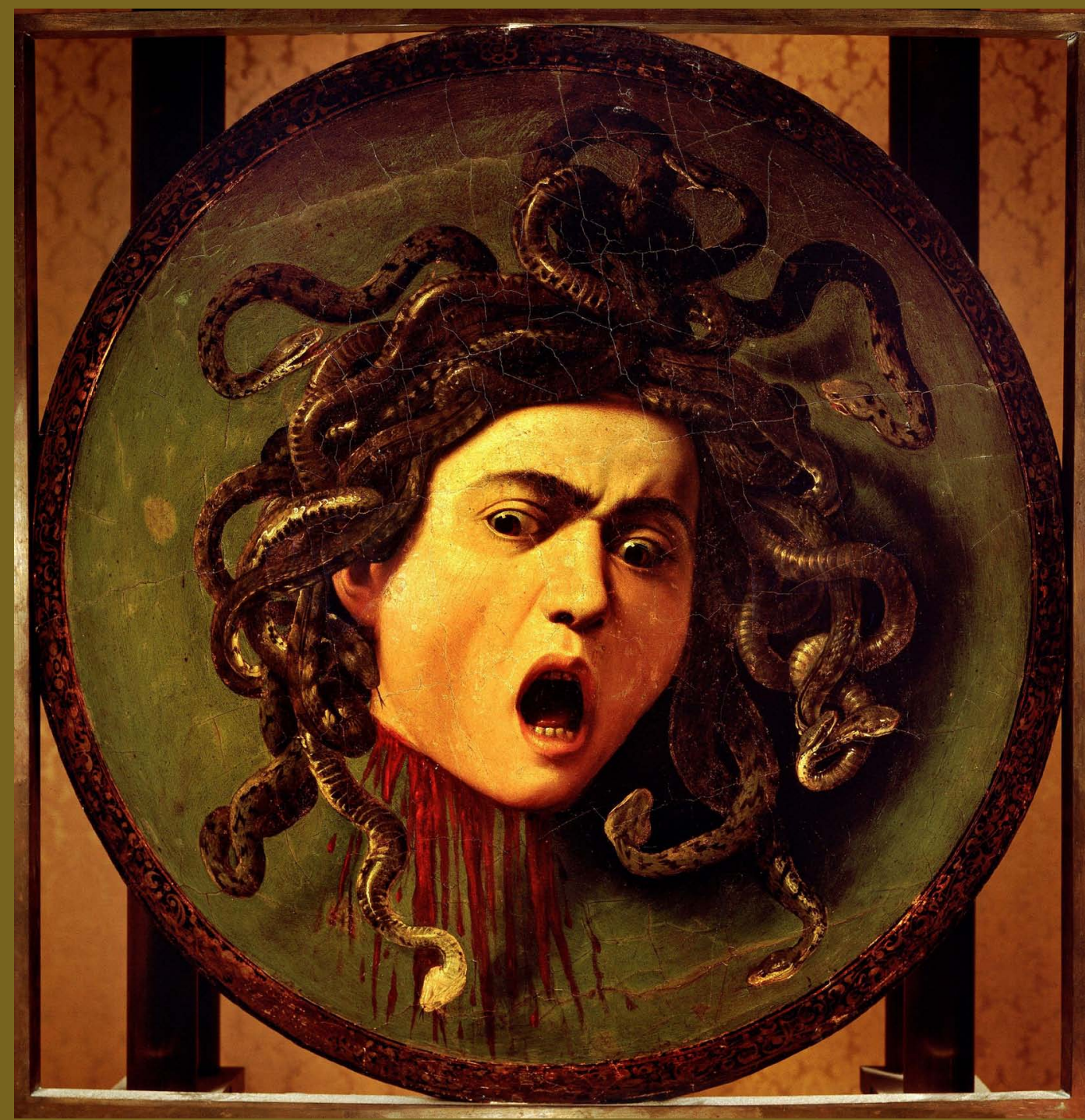

\section{R E V I S T A}
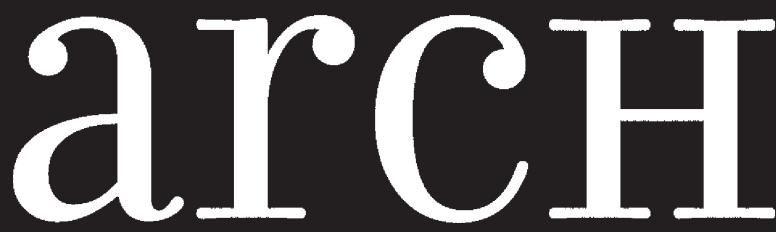
AS ORIGENS DO PENSAMENTO OCIDENTAL

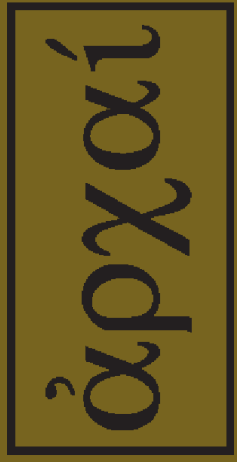

ARCHAI JOURNAL: ON THE ORIGINS OF WESTERN THOUGHT
arcHaI

arementam

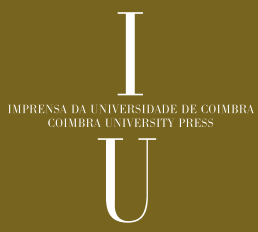

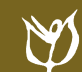

NNN 


\section{0 ÚLTIMO FOUCAULT E O RETORNO TRANSVERSAL AOS GREGOS}

GOMES, D. 0. (2012). “0 último Focault e o retorno transversal aos gregos". Archai n. 9 , jul-dez 2012, pp. 37-44.

RESUMO: A obra do filósofo Michel Foucault é usualmente repartida pela crítica em três fases/etapas. As duas primeiras fases são o chamado período arqueo-genealógico e, após estas fases, sob a herança nietzschiana, temos um último Foucault. $A$ fase final do autor, entretanto, marca um último Foucault que não deixa de caracterizar um "único Foucault." Esta fase de sua obra trata de um retorno transversal à cultura greco-romana (temas do uso dos prazeres e a técnica de si). 0 presente artigo analisa o retorno de Foucault ao primordial elo grego entre ética e estética e pergunta-se sobre a relação entre a antiguidade filosófica e a atualidade do pensamento foucaultiano.

PALAVRAS-CHAVE: gregos, epicurismo, Foucault, técnica de si, ética

ABSTRACT: The work of Michel Foucault is usually divided by the critics in three phases/stages. The first two ones are called the archeo-genealogical phase and, after this phases, under the Nietzschian inheritance, there is a last Foucault. The last phase of the author, however, defines a last Foucault that characterizes still a "unique Foucault". This phase of his work is about a transversal return to the greek-roman culture (themes about the use of pleasure and care of the self). The present article analyzes the Foucault's return to the main Greek link between ethics and aesthetics and also asks about the relation between ancient philosophy and the actuality of Foucault's thought.

KEY-WORDS: Greeks, Epicureanism, Foucault, care of the self, ethics
* Doutor em Literatura pela Universidade Federal de Santa Catarina. Professor adjunto na Universidade Estadual do Centro-0este - Paraná.

\section{Daniel de Oliveira Gomes*}

“E, no entanto, isto não é um retorno aos gregos, pois nunca há retorno" (DELEUZE, 1988, p.113)

\section{1) Fases/etapas de Foucault \\ Considerando a obra foucaultiana como uma} tripartite cronológica, teríamos a sabida atribuição pedagógica de períodos que, o mais das vezes, não deixam de ser genealogicamente interconectados em constantes recorrências temáticas e discursivas. Sabemos que ao primeiro período, a chamada fase arqueológica de Foucault, estão atribuídos os textos desde "Doença mental e personalidade" (1954) até "A ordem do Discurso" (1971); a segunda fase, a que trata das problemáticas relativas ao poder, iria desde então até o primeiro volume da "História da Sexualidade" (1976); a terceira fase, quando Foucault se dedica mais à subjetividade, visando a filosofia como um estilo de vida e não tanto uma caça da verdade, é quando rediscute a ética como um campo desvinculado da moral.

Seria nesta última fase que, conforme Vera Portocarrero, Foucault "circunscreve a temática da subjetividade numa reabilitação tanto de uma ontologia do presente quanto da concepção de Filosofia como exercício espiritual a ser atualizado." (PORTOCARRER0, 2006, p.282). Mas desde a 
fase da arqueologia, que consistia em investigar as condições da "archè" (o princípio) do conhecimento e seus esquemas fundantes, Foucault distingue duas tradições da Filosofia moderna: uma, onde o que se levanta é a questão da verdade; outra tradição, a de tornar o estrado da ontologia, no campo filosófico, muito mais abrangente, englobando também uma ontologia do presente, cuja discussão inovadora deveria ser a dos subsídios do nosso entorno com relação à ética do sujeito. Este tema da ética, entretanto, Foucault aprofundará em sua última fase, retomando as questões iniciais para propor uma inovação quanto ao “objeto dessa problematização, o sujeito, em sua relação com a ética. Nesse domínio muito clássico da filosofia, Foucault procede ainda uma vez à inversão da ótica tradicional, ao dissociar a moral da ética." (DOSSE, 2007, p.425)

Tradicionalmente, a Ontologia é um campo de análise delimitado pela investigação das estruturas metafísicas do ente. Fazer a ontologia do presente significaria, portanto, reunir dois domínios incompatíveis: a História e a Metafisica. Contudo, a leitura foucaultiana da definição kantiana das Luzes aponta claramente para um cruzamento entre reflexão crítica sobre o uso da razão e a reflexão histórica sobre a finalidade interior do tempo. E é justamente ao inseri-la neste contexto que sua reflexão sobre a atualidade torna-se relevante. (PORTOCARRERO, 2006, p.283)

\section{2) Louco, raposa, terceiro, último}

Não apenas o segundo e/ou o último Foucault abalou heterotopias. Ele punha-se, desde a primeira fase, como uma via de acesso a essa ontologia do presente; propunha-se a si mesmo como uma possibilidade dentre tantas, de estabelecimento de uma analítica das condições do arquivamento do saber, efetuando uma nova abrangência orientada ao tempo da atualidade. Assim sendo, o próprio pertencimento de uma voz arqueológica, que ele reivindica como base de sua obra, acaba sendo antes a supressão sistêmica de outras vozes que caminham junto a esta. É antes uma questão de supor, em Foucault, a metodologia de um apagamento que auxilie rumo ao regime de discursos que configuraram a história do conhecimento. A questão não está, especificamente, em enaltecer uma voz própria, inédita, ou política, que nos proporcione o grande achado foucaultiano. Talvez por isto Edson Passetti se refira à Foucault como um elemento extremamente nocivo, em um artigo, vendo-o como "louco, raposa, terceiro, último, um único Foucault" (p.109). Neste aspecto é que em Foucault ocorreria uma coesão tal que põe em risco a divisão de sua obra em três fases absolutamente categóricas. No último Foucault, teríamos um único Foucault, um jogo que se fecha e se abre propondo um Foucault que aparece para fazer desaparecer o sistema sem falhas, ou melhor, trabalhando as falhas do sistema, pondo em grau máximo de aparência as suas crises, conjunturas, anormalidades.

Não se trata, em absoluto, de um recolhimento, como mostra Pierre Macherey, mas de pensar condições de possibilidade do exercício de liberdade no interior de uma estrutura. Pensar consiste, assim, em situar-se nos limites, nas fronteiras dos sistemas de pensamento para deslocar-lhes as linhas. Isso nos leva à tragédia pessoal que vive Foucault, vítima de devastações causadas pelo trabalho da morte em seu próprio corpo: "Em L'usage dês plaisirs tentei mostrar que existe uma tensão crescente entre o prazer e a saúde". Essas palavras de Foucault traduzem bem o horizonte autobiográfico que adota aqui o desvio da problematização filosófica para permitir um trabalho de si sobre si, de reação contra a doença que o afeta, e reforça de maneira insuportável a marginalidade em que é mantida a homossexualidade, ao preconizar uma moral pós-convencional. Vai buscar seus fundamentos fora dos imperativos de interiorização da pastoral cristã ou da psicanálise, na ética do mundo antigo percebida como estética da existência e, portanto, lição para 'fazer de sua vida uma obra'. (DOSSE, 2007, p.426)

\section{3) A "pratique de soi"}

A "pratique de soi" alude às formas de subjetivação que o filósofo estudou desde o período helenístico arcaico e clássico, passando pelos romanos e os momentos de instrumentalização da moral cristã, até o período de estabelecimento dos chamados "biopoderes". Essas práticas de si mesmo 
são um tópico que Foucault retomará, em especial e com mais afinco, em seus derradeiros trabalhos, e onde a conjuntura será compreender os processos de constituição da existência do sujeito para si mesmo e em sua relação com o mundo. Não se trataria do fim da luta em si para atingir a paz com os outros; no entanto, ao contrário, trata-se de precisamente confrontar-se esteticamente numa esfera agonística, o que o filósofo muito bem apreende das intuições bélicas de Nietzsche. Em ensaio intitulado “Foucault com Nietzsche: do Nietzsche trágico ao Foucault ético", a professora da UFRGS Luciana Loponte afirma:

Há muito tempo confinamos a arte em suntuosos museus, emoldurando-a como objetos seletos, apartando-a da vida cotidiana. Se ainda lembramos Nietzsche, as obras de arte são apenas a sobremesa, e a refeição principal é a nossa própria vida como obra de arte. Mas de que forma podemos pensar na arte como forma de vida, como um modo de existência ético e também político? As últimas teorizações foucaultianas, fortemente inspiradas em Nietzsche, trazem uma outra dimensão para pensarmos a arte como um modo de existência, para pensarmos em uma "estética da existência", uma ética artística para nós mesmos. (LOPONTE, 2009, p.120)

A existência se daria não apenas nas práticas de confiança sobre si mesmo, mas na sustentação de uma resistência ética/estética, ou um movimento de contra-vigilância, que não seria propriamente extenuante, mas sim prazeroso, experimental e criativo. 0 que estritamente atrela Nietzsche e Foucault neste momento é, além do retorno ao modus vivendi ético dos antigos gregos, a dimensão do agonismo. "Agonisme", nos explica por exemplo Philippe Chavallier, vem a ser um neologismo foucaultiano que diferiria de "antagonismo", posto que para Foucault o domínio da luta não está excluído do plano da liberdade do exercício de poder. Ao contrário, no sentido que não há uma História, uma Memória, o que temos é - segundo mostra a filosofia foucaultiana em seu próprio procedimento, sua aparição - uma multidão de histórias e memórias-fantasmas que entre si mesmas entram em confronto, rumo à consolidação histórica. A liberdade está, assim, no coração dos dispositivos de poder, não sendo pura espontaneidade com relação ao poder. Liberdade não se caracteriza no extremo oposto da batalha.

A questão problematizada por Foucault não é simplesmente a emancipação ou a libertação de todas as formas de poder, até porque as relações de poder não são simplesmente a fonte de todo mal, se entendemos, é claro, que as relações de poder podem ser compreendidas como estratégias pelas quais os individuos tentam determinar a conduta dos outros. Dessa forma, para Foucault o problema não consiste em tentar dissolver essas relações de poder 'na utopia de uma comunicação perfeitamente transparente, mas em procurar-se as regras de direito, as técnicas de gestão e também a moral, o ethos, a prática de si, que permitam nestes jogos de poder jogar com o mínimo possivel de dominação' (FOUCAULT, 1999B, P.412). (LOPONTE, 2009, pp.123, 124)

\section{4) A invenção de si}

0 poder que se põe como voz no próprio discurso de Foucault, no movimento de suas análises e escrituras, seria menos a de um sujeito filosófico à priori, bem sabemos. Seria, sim, mais o poder de um sujeito atópico certo modo desmantelado de sua própria fala, que vai se constituindo ontologicamente no próprio movimento do discurso: é a voz de uma ontologia do presente no filósofo. É assim que Foucault se expunha em suas aulas e conferências, pelo que se sabe. É assim que ele se vale por Maurice Florence para falar de si mesmo, de sua importância como alocução na tradição ocidental da filosofia, propondo uma metalinguagem filosófica sob voz de "um outro". M. Florence explicitará que Foucault buscava, ante tudo, o modo de subjetivação do sujeito pensante, investigar sob quais condições um fato, um alguém, pode se tornar sujeito da filosofia ou objeto dela. A delicadeza e o respeito ético em sua obra estão no fato de que jamais se tratou propriamente da busca de um novo código e sim de argüir acerca do inexplicável com o qual aquilo que titulamos hoje de Filosofia, História, Medicina, Psiquiatria, Justiça, etc, instituíram-se como discursos importantes e fundadores de verdades, no mundo ocidental. 
A invenção de si, no entanto, não é um ato puramente individual, narcísico ou superficial, apesar de alguns críticos interpretarem essa estética da existência como uma forma de conformar os sujeitos a uma 'estetização objetiva como bonecas decorativas' (WELSCH, 1995). A relação com os outros, o cuidado com os outros, era fundamental para a noção de cuidado de si na Grécia antiga. A ética de si mesmo implica uma relação complexa com os outros, apesar do cuidado de si ser ontologicamente a relação primordial. (FOUCAULT, 1999b, p.400). 0 governo dos outros está estritamente relacionado com o aprendizado sobre o governo de si mesmo. E é nesse sentido que se inserem as práticas de si como a escrita de si (por meio dos hypomnemata e das correspondências) e as relações de amizade. (LOPONTE, 2009, p.123)

Blanchot nos lembra no final do livro "Foucault tal como o imagino" que, certa ocasião, ao ser interrogado por Hubert Dreyfus e Paul Rabinow sobre seus projetos, Foucault respondeu exclamativamente que queria se ocupar de si mesmo. Blanchot lembrará que na seqüência de Nietzsche, o filósofo procurou nos gregos menos uma moral cívica do que uma ética que lhe permitisse a si mesmo viver, fazer de sua vida uma resistência, como uma obra de arte. A questão que levanta é se Foucault buscou inventar a si mesmo para poder idear sua filosofia, fechando com chave de ouro sua última fase ao retomar os gregos, ou se sua filosofia mesma o inventou... 0 “invento-Foucault" está ainda em aberto, em estado de amizade, experimentação, cuidado, resgate helênico, invenção de si.

\section{5) Golpes de martelo}

Aqui, perguntamo-nos sobre a atualidade do pensamento foucaultiano e sobre as condições que seu retorno aos gregos (o uso dos prazeres e as técnicas de si), sob a herança nietzschiana, pode auxiliar aos novos pensadores em uma contemporaneidade já carregada de conhecimentos. A filosofia de Foucault está em condição de admiração exilada, de beleza, de paixão microfísica, contemplando as minúcias do mundo e de si? Pode ser, mas desprende-se, metafilosoficamente, em eterno movimento também. Conforme diria Pablo Perera Velamazán, estamos, ante tudo, diante de um "pensamento que se pensa a si mesmo" (p.118). 0u, diríamos, ocorre que: no movimento em que se dá o pensar, o pensamento pensa-se a si próprio. Como se o mundo de fora se chocasse contra o martelo ético do pensamento. 0 martelo do pensamento chocado, chocante, admirado, dentro/fora.

Talvez fosse mesmo preciso voltar aos gregos... Assim o problema mais passional encontraria condições que poderiam torná-lo mais frio ou acalmá-lo. Se a dobra, se a reduplicação obceca toda a obra de Foucault, mas só encontra seu lugar tardiamente, é porque ele exigia uma nova dimensão, que devia se distinguir ao mesmo tempo das relações de forças ou de poder, e das formas estratificadas do saber: 'a absoluta memória'. A formação grega apresenta novas relações de poder, bem diferentes das velhas formalizações imperiais e que se atualizam à luz grega como regime de visibilidade, no logos grego como regime de enunciados. (DELEUZE, p. 106)

A questão estaria não em apenas observar como o mundo presente é construído, as regras segundo as quais o pensar-hoje se arquiteta, bem como em, arrojadamente, conseguir desmontá-lo, desinstruí-lo, deslegitimar o já-dado para fazer da agoridade um experimento como contingência vazia, abandonada. A importância de abrir brechas. Brechas para qual lado? 0 lado de dentro, perguntaria Deleuze, ou lado de fora? Deleuze mesmo articularia "o lado de dentro do lado de fora" (p.104), quando fala de Foucault em "As dobras ou o lado de dentro do pensamento". Lembrando que, deleuzeanamente, encontramos três dimensões com Foucault: a primeira, formalizada sobre os estrados (Saber); a segunda, referente às relações de força ao nível do diagrama (Poder) e a terceira, a relação com o lado de fora, que seria já uma não-relação igualmente (Pensamento). Paul Veyne lembra o prazer que Foucault tinha em repetir que a filosofia de Nietzsche (o guerreiro-pai) não era a da verdade, mas a do dizer-verdadeiro. É a herança do alento do guerreiro, para quem o centro é inacessível. 0 guerreiro destrói (ou melhor, desconstrói). Kleber Prado Filho, no prefácio de "Foucault com outros nomes: Lugares de Enunciação", encontra na metáfora instrumental 
do "martelo" (que muito bem remete à energia para com o lado do fora) para dizer que o grande desafio do pensamento crítico de Foucault está em:

...na herança da desconstrução nietzschiana, destruir nosso mundo a golpes de martelo - marteladas filosóficas, claro! Então, para realizar sua proposta, seu pensamento precisa se manter atual para se manter vivo e ativo. Em última instância, perguntar sobre a atualidade de suas análises é questionar a potência de seu pensamento como caixa de ferramentas capaz de desmontar nosso mundo, nossas experiências históricas, abrindo brechas em termos de transgressões aos discursos, resistências aos modos de objetivação e subjetivação aos quais estamos sujeitos, assim possibilitando o exercício de práticas de liberdade. (PRADO FILHO, 2009, p.8)

\section{6) Foucault e o prego entre ética e estética}

Em “La hermenêutica del sujeto", Foucault exporá que a tecnologia de si:

"... ha conocido en el periodo helenístico y romano un gran desarrollo hasta el punto de haber absorvido una buena parte de la actividad filosófica. Este desarrojo no se puede separar del crescimiento de la sociedad urbana, de las nuevas distribuiciones del poder político ni de la importancia adquirida por la nueba aristocracia de turno en el Imperio romano. Este govierno de sí, com las técnicas que le son propias, se emplaza 'entre' las instituiciones pedagógicas y las religiones de salvación. (FOUCAULT, p.31)

Nisso que costumeiramente se chama sua última fase, Foucault procura "repregar" o primordial elo grego entre ética e estética, elo entre o ideal da bondade e o ideal da perfeição - compreensão esta que foi obviamente extraviada nos novos paradigmas de auto-restrição que o asceticismo grego cede espaço ao código da renúncia de si em nome da verdade cristã, que funda toda base para a modernidade do ocidente. 0 filósofo fará então uma série de viagens à Polônia, Canadá, Japão e aos Estados Unidos, em busca de averiguar e apresentar academicamente o resgate de uma técnica de si diferente daquela formulada e instaurada desde o aparecimento do cristianismo e ainda antes - posto que ele rejeite “uma ruptura moral entre uma Antiguidade tolerante e um cristianismo austero" (PORTOCARRERO, 2006, p.287). Em verdade, Foucault encontra-se a si mesmo em sua última fase, pois, já no primeiro Foucault, veremos que o sujeito está excluído, desqualificado, como voz fundamental da verdade; de modo que desde sempre Foucault laborava uma versão de sujeito em constituição a si mesmo muito distinta da metafísica moderna ou das velhas práticas de austeridade, entendendo-o, por sua vez, como decorrência do discurso e em relação ambivalente para com o fora do mundo, a exterioridade, etc. 0 sujeito está sempre em movimento dúbio de constituição, como um foco de resistência à interioridade, efeito-sujeito descontínuo.

A exigência ética própria da articulação entre subjetividade e verdade é privilégio, ainda que não exclusivo, da filosofia antiga, particularmente entre estóicos e epicuristas. Seguindo os rastros de Pierre Hadot, que destaca a importância dos 'exercícios espirituais' em tais filosofias, Foucault se refere a elas como 'espiritualidade antiga.' Esta designa 'a busca, a prática, a experiência mediante as quais o sujeito opera sobre si próprio as transformações necessárias para ter acesso à verdade' (Foucault, 2001, p16), porquanto tal como ele é, não poderá adquiri-la. Segue-se que a modificação do modo de ser é fundamental para subjetivar discursos reconhecidos como verdadeiros. Os discursos (logói) são qualificados de verdadeiros se atuam como princípios e matrizes de ação, de modo a formar no indivíduo a atitude e a disposição necessárias para enfrentar os acontecimentos da existência.

Na espiritualidade antiga, a verdade, tal como ela é - no sentido de matriz de ações - pode transformar o sujeito na medida em que ele sempre é desqualificado para ser fundamento de verdade. Importante é ressaltar que alguém subjetiva discursos verdadeiros ao modo de conselhos para a ação ou de preparação adequada para as vicissitudes da existência. Ao mesmo tempo em que a ética do sujeito aponta os limites filosóficos do privilégio moderno do conhecimento de si, no qual o sujeito já é capaz de verdade, ela também qualifica os modos de 
aquisição antigos dos discursos verdadeiros mediante a

ascese do cuidado consigo. (CANDIOTTO, p.90)

É um trabalho intenso e audacioso, mas que acaba por agregar toda a obra do filósofo, oportunizando uma linha de coerência para se pensá-lo - mesmo sob o paradoxo do dentro/fora, interior/ exterior, que sustenta o tempo todo -, cabalmente, em sua investigação. Como dirá Deleuze, "o que os gregos fizeram não foi revelar o Ser ou desdobrar o Aberto, numa gesta histórico-mundial. Foi muito menos, ou muito mais, diria Foucault. Foi vergar o lado de fora, em exercícios práticos. Os gregos são o primeiro forro (doublure)."(DELEUZE, p.108). Sob o diagrama das relações de poder característico dos gregos, somente os homens livres poderiam dominar os outros, de modo que era preciso dobrar esta dominação sobre os outros dominando primeiramente a si mesmo, tornando-se subalterno e soberano (também vigorado isso no plano da sexualidade, do casamento, dos assuntos citadinos, da alimentação, etc). Ou seja, fazendo a força (do fora) correlacionar-se com si mesma e não estando, assim, a ignorar o sujeito, mas ao contrário a inventá-lo, a colocá-lo como obra de uma subjetivação, sob uma existência estética.

Em Foucault, segundo Deleuze, a idéia de resgatar estas lições antigas, de Platão, Xenofonte, Sócrates, Epicuro, Plutarco, etc, está em "uma dimensão da subjetividade que deriva do poder e do saber, mas que não depende deles" (Deleuze, p.109). Porém, em Foucault, estamos ainda a pensar de outro modo - um modo transversal, um golpe transformador, um modo de vida etopoético ${ }^{1}$, resistente, pregado como a baques de martelo: devolver à atualidade suas próprias patologias e instabilidades já sabidas. Retornar aos gregos não é propriamente retornar aos gregos? Será mais uma dobra de Foucault em direção ao seu próprio trabalho, a si mesmo... Anunciar, a partir daí, uma palavra plural acerca das indisposições que, segundo alguns sintomas identificáveis (construídos, inventados, desconstruídos), podemos capturar a carcaça do presente para o diagnóstico. De-discere - desaprender - a tarefa primordial do cultivo de si dentre a antiga cultura greco-romana.

\section{REFERÊNCIAS BIBLIOGRÁFICAS}

BLANCHOT, M. (1986) Michel Foucault tel que je l'imagine. Paris: Éditions Fata Morgana.

BÉNATOUÏL, T. (2004) “Dos usos del estoicismo: Deleuze y Foucault". Foucault y la filosofía antigua, Frédéric Fross y Carlos Lévy (org.), Buenos Aires: Ediciones Nueva Visión.

BRUNO, M. (2007) "A Função Etopoiética da Escrita". Foucault hoje?, André Queiroz e Nina Valasco e Cruz (org.), Rio de Janeiro: 7 Letras.

CANDIOTTO, C. (2008) "Subjetividade e Verdade no Último Foucault". Trans/Form/Ação, São Paulo, 31(1): 87-103.

CHEVALLIER, P. (2004) Michel Foucault. Le pouvoir et la bataille, Nantes: Éditions Pleins Feux.

DELEUZE, G. (1988) Foucault. São Paulo: Brasiliense.

DOSSE, F. (2007) “Michel Foucault: do biopoder à estética de si". História do Estruturalismo, volume II, trad. Álvaro Cabral, Bauru: EDUSC.

FOUCAULT, M. (1999) Arqueologia das Ciências e História dos sistemas de Pensamento. Manuel Barros da Motta (Org.) Rio de Janeiro: Forense Universitária.

.(1996) “La hermenêutica del sujeto. Conclusiones de los cursos 1980-1982". Revista de Filosofia Anábasis, Madrid, ano III, n. 4.

. (2000) Tecnologias del yo. Y otros textos afines. Trad. espanhol de Mercedes Allendesalazar. Barcelona: Paidós/I.C.E.-U.A.B.

.(2001) "Conferência 2" in A verdade e as formas jurídicas, Rio de Janeiro: Nau ed.

. (1985) História da sexualidade - v. III - 0 cuidado de si. Rio de Janeiro: Graal.

FLORENCE, M. (1996) "Foucault, Michel, 1926 (-1984)". Revista de Filosofia Anábasis, Madrid, ano III, Núm. 4.

GOMES, D. de 0., SOUZA, P. de, (org). (2009) Foucault com outros nomes. Lugares de enunciação. Ponta Grossa: UEPG.

GROSS, F. (2006) "0 cuidado de si em Michel Foucault", trad. Margareth Rago e Alfredo Veiga-Neto. Figuras de Foucault, Belo Horizonte: Autentica.

JAFFRO, L. (2004) “Foucault y el estoicismo. Acerca de la historiografía de L'herméneuthique du sujet". Foucault y la filosofía antigua, Frédéric Fross y Carlos Lévy (org.), Buenos Aires: Ediciones Nueva Visión.

LOPONTE, L. G. (2009) “Foucault com Nietzsche: do Nietzsche trágico ao Foucault ético. Foucault com outros nomes. Lugares de enunciação. Pedro de Souza e Daniel de Oliveira Gomes (org.). Ponta Grossa: UEPG.

NIETZSCHE, F. (1999) Além do Bem e do Mal. Prelúdio a uma filosofia do futuro. Trad. Paulo César de Souza. 2 ed, São Paulo: Cia das Letras.

PASSETI, E. (2006) "Heterotopia, anarquismo e pirataria". Figuras de Foucault. Margareth Rago e Alfredo Veiga-Neto (org.), Belo Horizonte: Autêntica.
1. No breve ensaio: "A Função Etopoiética da Escrita", Mário Bruno nos fala dos monges eremitas, do início da era cristã, que se isolavam no deserto, sendo conhecidos como anachoretas. Explica-nos que, sob vários aspectos, a anachorese aproximase do modelo da enkratéia, no entanto, “(...) é preciso que sejam estabelecidas certas distinções. A enkratéia era uma atitude grega necessária à ética dos prazeres, manifestava-se no bom uso que se fazia deles (FOUCAULT, 1984 p.60). A anachorese embora foss bem anterior ao cristianismo, ficou conhecida como um exercício particular cristão de relacionamento consigo, que comportava modos precisos de atenção, de suspeita, de renúncia e de combate espiritual. A enkratéia e a anachorese eram práticas do cuidado de si no 0cidente. A primeira visava ao domínio do corpo e dos prazeres; a segunda objetivava o domínio da carne e do desejo (DELEUZE, 1984, pp.141-2)". (BRUN0, 2007, p.44.) 
PORTOCARRERO, V. (2006) “Práticas sociais de divisão e a constituição do sujeito". Figuras de Foucault, Margareth Rago e Alfredo Veiga-Neto (org), Belo Horizonte: Autentica.

SOUZA, P. de. (2009) Michel Foucault. 0 trajeto da voz na ordem do discurso, Campinas, Editor RG.

TROCQUER, 0. (2001) Un événement en quête d'auteur. JACQUES-LEFEVRE, N. ; REGARD, F. (Orgs.). Une histoire de la 'fonction-auteur' est-elle possible? Saint-Étienne: L'Université de Saint-Étienne.

VELAMAZÁN, P. P. (1996) "Pensar de otro modo: Dos variaciones en torno a Michel Foucault." Revista de Filosofia Anábasis, Madrid, ano III, n. 4.

VIALA, A. (1999) Naissance de l'écrivain. 'Sociologie de la litterature à l'âge classique'. Paris: Les Éditions de Minuit.

Recebido em dezembro de 2011.

Aprovado em janeiro de 2012. 